\title{
Artikel $\mid$ MATE : Men's Assistant Tracker on Health GAGASAN PEMBUATAN APLIKASI PENGONTROL KESEHATAN HARIAN PADA LAKI-LAKI
}

\section{Penyegar}

\section{Prilly Mutiara Sandy}

Universitas Padjajaran, Jawa Barat

Coresponding author's email : prillymutiaras@gmail.com

\begin{abstract}
ABSTRAK
Menurut data WHO pada tahun 2012 menunjukkan bahwa kematian laki-laki secara global adalah sebanyak $52 \%$ dan disebabkan oleh penyakit yang tidak menular (NCD). Jika dibandingkan dengan wanita, laki-laki lebih mungkin tutup usia sebelum waktunya (dibawah 70 tahun) akibat NCD di hampir setiap negara. Kemudian, terdapat survey di Asia yang menunjukkan bahwa harapan hidup laki-laki lebih rendah daripada wanita dan merupakan pertanda perlunya peningkatan dalam status kesehatan laki-laki tentang masalah kesehatan yang dapat dicegah dan mendorong deteksi dini serta pengobatan penyakit pada laki-laki. Dengan adanya edukasi, kesadaran mengenai kesehatan diri akan meningkat, dan juga meminimalisir pemahaman yang salah tentang kondisi klinis pada laki-laki. Karena laki-laki pada umumnya menghindari untuk bertemu praktisi kesehatan,lalu memantau dan mengobati sendiri gejala,serta menghilangkan anggapan mempunyai penyakit (walaupun mengalami gejala). Di era teknologi ini, informasi akan lebih mudah didapat jika diakses dalam media digital, seperti: melalui online platform MATE: Men's Assistant Tracker on Health yang bisa diakses kapanpun dan dimanapun. Aplikasi ini mengedukasi baik secara general maupun spesifik tentang kesehatan laki-laki dan berfokus pada deteksi dini penyakit yang dikombinasikan dengan saran gaya hidup dengan tiga konten utama, yaitu: Daily Tracker, Health Insights, dan Community.
\end{abstract}

Kata kunci: Aplikasi, Men's Assistant Tracker on Health, Penyakit Tidak Menular

\section{ABSTRACT}

According to WHO data in 2012 showed that global male mortality was 52\% and was caused by non-communicable diseases (NCD). Compared to women, men are more likely to die prematurely (under 70 years) due to NCD in almost every country. Then, there is a survey in Asia that shows that life expectancy for men is lower than for women and is a sign of the need for improvement in men's health status about preventable health problems and encourages early detection and treatment of diseases in men. With education, awareness about personal health will increase, and also minimalize the wrong understanding of the clinical condition in men. Because men generally avoid to meet health practitioners, then monitor and treat their own symptoms, and eliminate the perception of having a disease (despite experiencing symptoms). In this technological era, information will be easier to obtain if accessed in the digital media, such as: via an online platform MATE: Men's Assistant Tracker on Health that can be accessed anytime, anywhere. This application educates both general and specific about men's health and focuses on early detection of diseases combined with lifestyle advice with three main contents, namely: Daily Tracker, Health Insights, and Community.

Keywords: Application, Men's Assistant Tracker on Health, non-communicable diseases

\section{PENDAHULUAN}

Kesehatan laki-laki dipengaruhi oleh beberapa faktor seperti aspek mental, fisik, emosional, sosial dan spiritual dari kehidupan mereka; keluarga, komunitas dan lingkungan. Dalam aspek biologis, terdapat dampak kromosom $\mathrm{Y}$ pada tubuh laki-laki dan pengaruh testosteron pada manusia (dan hampir semua spesies lain) dalam hal berperilaku. Laki-laki seringkali tidak menempatkan kesehatan sebagai prioritas. Sifat laki-laki yang menjadi stereotip seperti kemandirian dan berani mengambil resiko menjadi salah satu penghambat untuk terlibat dalam perilaku kesehatan yang positif(1). 
Data WHO pada 2012 menunjukkan bahwa $52 \%$ dari semua kematian akibat penyakit yang tidak menular (NCD) adalah lakilaki secara global. Dibandingkan wanita, lakilaki lebih mungkin tutup usia sebelum waktunya (dibawah 70 tahun) akibat NCD di hampir setiap negara (hanya di empat negara adanya kemungkinan perempuan untuk tutup usia sebelum waktunya). Proporsi kematian dini NCD pada laki-laki dua kali atau lebih jika dibandingkan dengan kematian perempuan yang hanya $24 \%$ dalam NCD. Faktor resiko utama untuk NCD yaitu pola makan yang tidak sehat, pengguanaan rokok atau tembakau dan penggunaan alcohol yang berbahaya. Namun, banyak kondisi kesehatan kronis pada laki-laki (diperkirakan 70\%) dapat dikaitkan dengan gaya hidup dan berpotensi dapat dicegah(2).

Kanker prostat adalah penyebab kematian dengan keganasan tersering. Di Asia, kejadian adanya kanker prostat rata-rata adalah 7,2 per 100.000 laki-laki per-tahun(3). Sedangkan jika di Indonesia pada tahun 2013, prevalensi kanker prostat adalah sebesar $0,2 \%$ o atau diperkirakan sebanyak 25.012 penderita. Di provinsi seperti D.I. Yogyakarta, Bali, Sulawesi Utara, dan Sulawesi Selatan, prevalensi kanker prostat sebesar $0,5 \%$ dan dapat digolongkan memiliki prevalensi tertinggi dibandingkan provinsi lainnya. Kemudian jika berdasarkan estimasi jumlah penderita, penyakit kanker prostat terbanyak berada pada
Provinsi Jawa Tengah dan Provinsi Jawa Timur(4).

Depresi laki-laki pada tahap awal seringkali berbeda gejala dengan apa yang yang dialami oleh wanita. Sering dimanifestasi dengan perilaku mudah marah, agresif, kasar, mengambil resiko, penyalahgunaan obatobatan dan perilaku tidak produktif.

Pemahaman yang salah tentang depresi pada laki-laki terjadi karena laki-laki pada umumnya menghindari untuk bertemu praktisi kesehatan, memantau sendiri dan mengobati sendiri gejala,serta menghilangkan anggapan mempunyai penyakit (walaupun mengalami gejala). Pemahaman yang seperti ini dapat mempengaruhi bagaimana mengidentifikasi dan bagaimana mengobatinya(5).

Menurut survei yang dilakukan di Indonesia, ditemukan bahwa sebanyak 21,8\% responden mengalami gejala depresi sedang sampai berat. Dari prevalensi tersebut, tingkat gejala depresi yang lebih tinggi dimiliki oleh perempuan, namun dengan perbedaan yang tidak signifikan terhadap laki-laki. Berdasarkan survey, sebanyak 21,4\% laki-laki dan 22,3\% perempuan melaporkan gejala depresi sedang sampai berat. Dan laki-laki yang disurvei, lakilaki berusia 20-29 tahun menunjukkan prevalensi gejala depresi sedang atau berat tertinggi (29\%) dan setelahnya remaja laki-laki $(26,6 \%)$ dibanding kelompok usia lain(6).

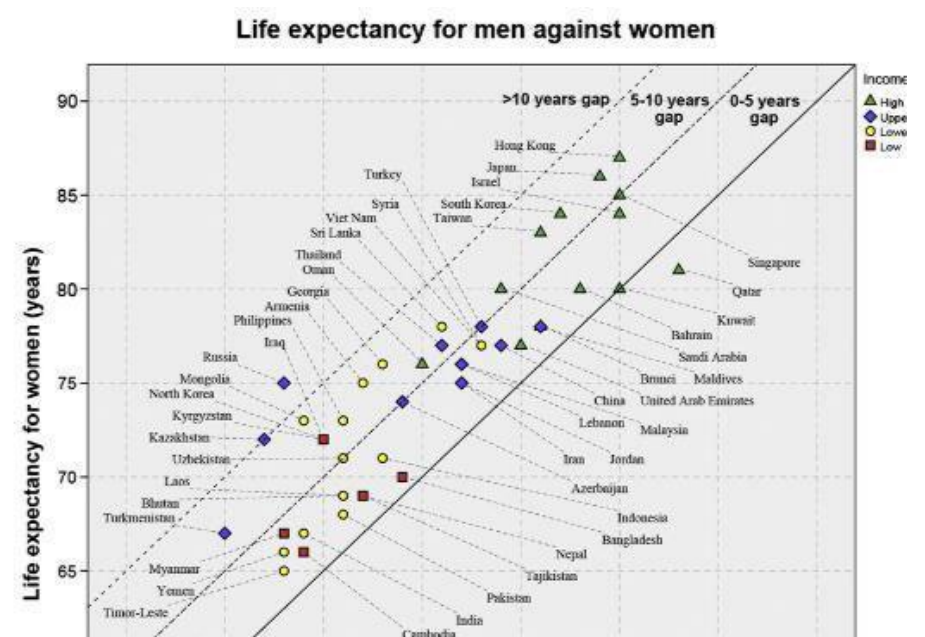


Gambar 1. Perbandingan angka harapan hidup antara laki-laki dan wanita di Asia di beberapa rentang usia dalam grafik(7).

Grafik diatas menunjukkan bahwa harapan hidup laki-laki lebih rendah dari wanita dan merupakan adanya pertanda perlunya peningkatan dalam status kesehatan lakilaki(7).

Berdasarkan pemaparan latar belakang, penulis mengangkat sebuah gagasan untuk membuat suatu aplikasi yang dapat digunakan sebagai online platform dalam edukasi kesehatan serta pengumpulan data kesehatan dari laki-laki tiap harinya. Melalui kajian komprehensif mengenai gagasan pembuatan aplikasi kesehatan tersebut diharapkan dapat meningkatkan kesadaran akan pentingnya menjaga kesehatan dan gaya hidup yang sehat di kalangan laki-laki.

\section{ISI}

MATE atau Men's Assistant Tracker on Health adalah sebuah aplikasi untuk mengedukasi baik secara general maupun spesifik tentang kesehatan laki-laki. Serta adanya fitur 'tracker' aspek fisik maupun biologis dari laki-laki yang menjadi teman dalam kesehariannya karena mencatat setiap informasi kesehatan harian yang dialami oleh pengguna aplikasi ini. Dengan kemudahan akses berupa fitur online melalui aplikasi ini, bisa didapatkan di smartphone yang notabenenya digunakan sehari-hari. Yang akan ditampilkan dari aplikasi ini adalah spesifik mengenai masalah kesehatan mental dan kesehatan reproduksi berupa penyampaian edukasi, karena dengan adanya edukasi lebih lanjut, kesadaran akan pentingnya kesehatan akan bertambah. Dan juga berfokus pada deteksi dini penyakit yang dikombinasikan dengan saran gaya hidup.

Konten yang disajikan dalam aplikasi ini disesuaikan dengan kondisi tubuh pengguna setiap harinya. Ada 3 konten utama, yaitu: Daily Tracker, Health Insights, dan Community.

\section{Daily Tracker}

Daily Tracker ini difungsikan untuk mendata kondisi pengguna setiap harinya. Seperti pendataan berat badan, waktu tidur, jumlah air yang diminum, sudah berjalan kaki berapa jauh, mood tracker, gejala fisik seperti: sakit kepala; kram; konstipasi; mual dan masalah fisik lainnya, mengkonsumsi alkohol seberapa banyak, dan merokok berapa batang serta keinginan seksual.

\section{Health Insights}

Health Insights adalah berupa konten edukasi seperti timeline di media sosial pada umumnya. Isi dari konten ini bisa disesuaikan dengan daily tracker yang telah didata sebelumnya. Berupa video edukasi maupun video interaktif, lalu infografis, dan tulisan 
mengenai kesehatan pada laki-laki dan juga menampilkan fakta dan mitos tetntang kesehatan agar stigma yang bermunculan di kesehatan dapat dihilangkan dan memberi pemahaman baru tentang kesehatan pada lakilaki. Konten edukasi yang menarik dan informatif yang merupakan tujuan dari konten ini penting utnuk meningkatkan kesadaran kesehatan para laki-laki yang sering diabaikan oleh mereka. Dan jika malas check-up ke rumah sakit, bisa dilihat pada konten ini sudah seberapa parah masalah kesehatan tersebut dan menampilkan peringatan harus menghubungi dokter jika telah mengalami tahap keparahan tertentu.

\section{Community}

Konten yang ketiga ini adalah berupa sebuah wadah untuk menampung opini serta

menghubungkan pengguna satu sama lain untuk Berikut adalah contoh tampilan (dummy) dari membahas topik yang telah disediakan di aplikasi.aplikasi ini:

Tujuan ditentukannya topik ini adalah agar pembahasan dapat dilakukan secara spesifik dan menemukan jalan terbaik untuk mengatasi suatu masalah ataupun menghindari maslah tersebut. Topik yang diangkat adalah sesuatu yang menjadi sumber kemaslahatan laki-laki pada umumnya. Kemudian, setelah didiskusikan, dapat disempurnakan dengan opini dari para ahli kesehatan tersebut yang nantinya akan ditampilkan di konten Health Insights.Dan juga bisa menampilkan tentang acara seminar kesehatan.

Ketiga konten diatas sekiranya sudah memberikan gambaran tentang perlunya menjaga kesehatan dan menjalani hidup sehat. karena secara psikologis, dalam mendata perkembangan kesehatan setiap harinya adalh meningkatkan motivasi untuk menjadi lebih baik di kemudian hari. 

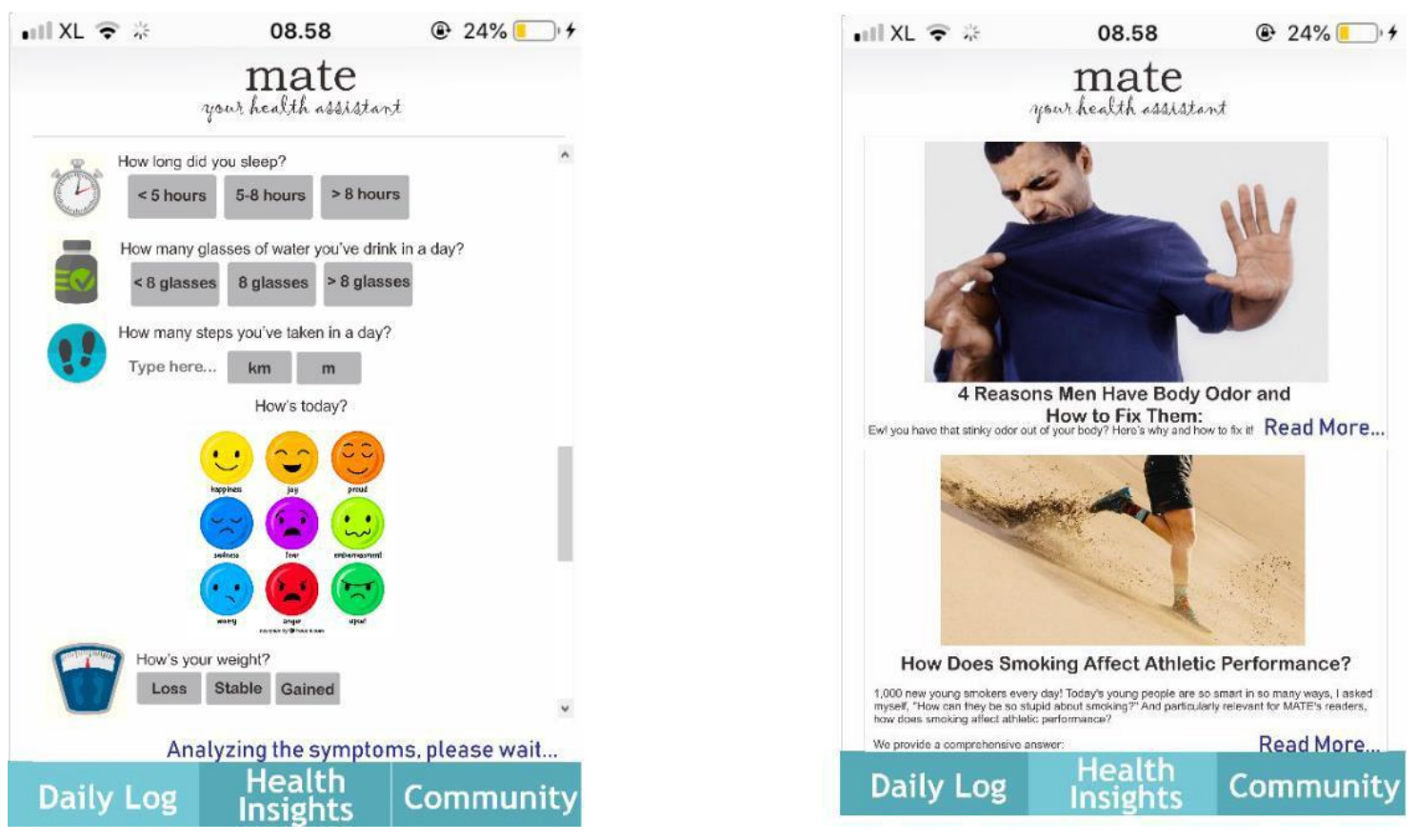

Gambar 2. Tab konten 'Daily Log' pada aplikasi MATE

Gambar 3. Tab Konten 'Health Insights' pada aplikasi MATE

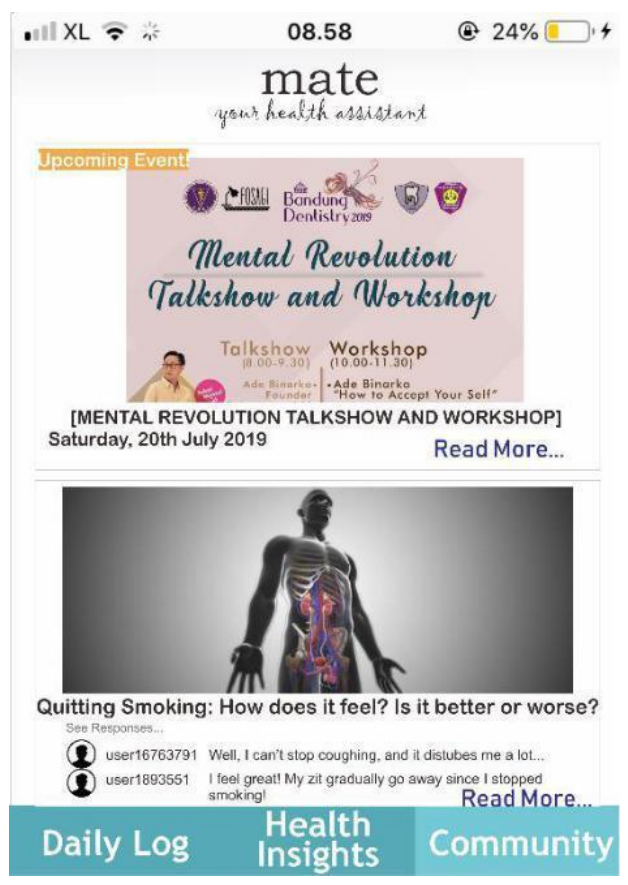

Gambar 4. Tab konten 'Community’ pada aplikasi MATE 


\section{PENUTUP}

Banyak dari laki-laki sering mengabaikan kesehatannya, menurut literature yang telah melibatkan beberapa responden, yang mana kesehatan mental dan reproduksi adalah hal yang sering terganggu di kalangna laki-laki. Dalam meningkatkan kesadaran kesehatan mental dan reproduksi pada laki-laki yang notabenenya penting sekali, perlu diadakannya edukasi lebih. Edukasi yang memadai bisa meningkatkan kesadaran kesehatan secara tidak langsung. Diharapkan dengan aplikasi ini bisa mendekatkan edukasi tentang kesehatan dengan cara yang praktis dan mudah dipahami, sehingga tidak adanya bias ataupun kesalahpahaman di dalam menjaga kesehatan ataupun cara mengobati suatu gejala penyakit.

\section{DAFTAR PUSTAKA}

1. Goldenberg SL. review Status of men 's health in Canada. Can Urol

Assoc. 2014;8(August):142-4.

2. Baker P, Shand T. Men's health: time for new approach to policy and practice? J Glob Health. 2017;7(1).

3. Kementerian Kesehatan Republik Indonesia. Paduan Penatalaksanaan Kanker Prostat. 2014;2.

4. Kemenkes RI Pusat Data dan Informasi. Stop Kanker. infodatin-Kanker [Internet]. 2015; hal 3. Available from: http://www.depkes.go.id/resources/download/ pusdatin/infodatin/infodatin-kanker.pdf

5. Mayor E. Gender roles and traits in stress and health. Front Psychol. 2015;6(JUN):1-7.
6. Peltzer K, Pengpid S. High prevalence of depressive symptoms in a national sample of adults in Indonesia: Childhood adversity, sociodemographic factors and health risk behaviour. Vol. 33, Asian Journal of Psychiatry. Peltzer, Karl: HIV/AIDS/STIs and TB (HAST), Human Sciences Research Council, Pretoria, South Africa, kpeltzer@hsrc.ac.za: Elsevier Science; 2018. p. 52-9.

7. $\mathrm{Ng} \mathrm{CJ}, \mathrm{Teo} \mathrm{CH}, \mathrm{Ho} \mathrm{CCK}$, Tan WP, Tan HM. The status of men's health in Asia. Prev Med (Baltim) [Internet]. 2014;67:295-302. Available from: http://dx.doi.org/10.1016/j.ypmed.2014.08.007 